\title{
An integrated model of psychological preparedness for threat and impacts of climate change disasters
}

\author{
I. G. Malkina-Pykh \& Y. A. Pykh \\ Research Center for Interdisciplinary Environmental Cooperation, \\ Russian Academy of Sciences (INENCO RAS), \\ Saint-Petersburg, Russia
}

\begin{abstract}
The reality of unfolding global climate changes and their increasingly evident impacts with respect to the frequency and intensity of natural disasters all over the world gives the matter of psychological preparedness for disasters a compelling currency and relevance. Psychological preparedness differs from household or physical preparedness in that what is referred to is an intraindividual and psychological state of awareness, anticipation, and readiness - an internal, primed, capacity to anticipate and manage one's psychological response in an emergency situation. Results of many studies suggest that personality is fundamental to the understanding of resilience and preparedness for disaster.

The aim of the present study was to apply the method of response functions (MRF) for the development of nonlinear integrated model of individual psychological preparedness from data and prior knowledge or information on several personality variables: trait anxiety, self-efficacy, dispositional optimism and self-esteem. The proposed model can be applied as effective assessment tool not only for the basic level of psychological preparedness but also for indication of the most important variables for pre-impact intervention.
\end{abstract}

Keywords: psychological preparedness, integrated model, psychological predictors, method of response functions.

\section{Introduction}

Natural disasters, such as floods, cyclones, tsunami, droughts, etc. are predicted to increase as a consequence of climate change. The series of disasters that 
happened just within this millennium - Hurricane Katrina, the tsunami in Indonesia and other countries, earthquakes in Haiti, New Zealand, Chile and Japan, the flooding in Sri Lanka, Pakistan, the Philippines, Australia, China, and Brazil - point out two things: disasters happen everywhere and they happen more frequently. Disasters are complex and uncontrollable events that can elicit a negative emotional response (e.g. stress, fear and anxiety). While such emotions are normal in response to perceived threat, an inability to manage stress can lead to a number of negative outcomes such as: a) cognitive disruption e.g. disorientation and problems with attention and memory, b) poor decision making and judgement, c) maladaptive behaviours e.g. denial and avoidance, and d) negative psychological outcomes post-disaster e.g. post-traumatic stress, depression, and anxiety.

The reality of unfolding global climate changes and their increasingly evident impacts with respect to the frequency and intensity of natural disasters all over the world gives the matter of psychological preparedness for disasters a compelling currency and relevance.

Pre-impact psychological assessment and intervention has been an area of surprising omission in multidisciplinary writings about human response to natural disaster. This is not to say that an extensive literature on human response to natural and man-made hazards does not exist, but much of this discourse relates to either post impact stress and coping issues or organizational preparedness and response (Morrissey and Reser [1]).

Disaster preparedness describes the self-protective or precautionary behaviours that can be harnessed to protect from hazard events threatening one's life and property (Duval and Mulilis [2]; Hobfoll [3]; Paton et al. [4]). In the disaster context, preparedness is an essential component of all disaster management models and frameworks, but typically focuses exclusively on what household preparations and actions one should take to protect oneself and family and to prevent or mitigate damage and human and financial costs and loss.

The most widely employed classification of disaster preparedness has three categories:

a) Material Preparedness: The material preparedness includes durable modifications of the household such as fixing tall and heavy furniture or water heater to the wall and possession of various pieces of equipment useful during a disaster such as food and water supplies, fire extinguisher or first aid kit.

b) Planning Activities: The preparedness activities include some arrangements. For example, determining a safe place in the house or identifying a meeting place outside the house.

c) Knowledge and Skills: The third category reflects individual's knowledge and skills about disaster itself and about preparedness methods such as joining a first aid course or reading the materials about preparedness.

Also, disaster researchers have posited many factors that could predict disaster preparedness behaviour. These factors include socio-demographic variables (e.g., age, household income, having school children in the home and level of education), and experiential components (e.g., having been through 
previous severe past earthquake experience, having relatives who suffered from injury or loss).

Psychological preparedness differs from household or physical preparedness in that what is referred to is an intra-individual and psychological state of awareness, anticipation, and readiness - an internal, primed, capacity to anticipate and manage one's psychological response in an emergency situation. Individual and community psychological preparedness in the natural disaster context has proven to be one of the most effective resilience-conferring strategies available in the context of natural disasters (Reser and Morrissey [5]).

We are aimed to draw the main focus from building codes, fire prevention, evacuation plans, and other important logistical and organizational preparations as well as proactive and resource-based theories of stress and coping and to develop a self-assessment tool that measures psychological resilience and preparedness for a disaster. Understanding psychological factors related to preparedness are central to the efforts to reduce the negative effects of disasters.

A better understanding of one's own and other's psychological response in natural disaster warning situations helps people to feel more confident, more in control and better prepared, both psychologically and in terms of effective emergency planning. Being cooler, calmer and more collected is also a substantial aid to family members and others who may not be as well prepared for what is happening. Psychological preparedness can assist people to think clearly and rationally, which in turn may reduce the risk of serious injury and loss of life (Reser and Morrissey [5]).

Psychological preparedness can play a crucial role in emergency preparedness, in coping with the stress of the unfolding situation, and in limiting acute post-incident distress.

\section{Predictors of psychological preparedness}

The value and effectiveness of psychological preparedness advice in natural disaster warning situations has received initial and promising empirical support (Morrissey and Reser, 2003), and draws from extensive, evidence-based clinical and health research literatures (e.g., Zeidner and Endler [6]).

Results of many studies suggest that personality is fundamental to the understanding of resilience and preparedness for disaster. A number of models of psychological preparedness exist based predominantly on proactive and resource-based theories of stress and coping, such as the Conservation of Resources Model (Hobfoll [3]), the Warning and Response model (Lindell and Perry [7]), and the Proactive Coping model (Aspinwall and Taylor [8]).

Mulilis and Duval [9] in their "Person Relative to Event Model" examined the self efficacy (beliefs regarding personal capacity to do something) and response efficacy (perceptions of whether personal actions will reduce a problem) as person variables, and severity (estimated degree of destructiveness of a potential earthquake) and probability of occurrence of event (the idea of the time of a potential earthquake) as event variables in predicting earthquake preparedness behaviour. 
These authors have identified how dispositional or personality factors play pivotal roles in this decision making process. It can thus be argued that certain internal traits, values, beliefs, cognitive processes, and defences play a role in how human-environment transactions are managed (Bishop et al. [10]; Mulilis et al. [11]; Sims and Bauman [12]). Human-environment transactions are often motivated by a need for people to feel that they can exercise control. Consequently, a belief in being able to exercise control has proven to have significant influence on people's hazard resilience. The constructs of locus of control and self-efficacy have thus been implicated as predictors of preparedness (Bauman and Sims [13]; Paton et al. [4]; Yates et al. [14]).

A great deal of prior research on disaster preparedness has been undertaken, with a number of key influences of preparedness identified (see Becker et al. [15] for a review). Key influences include risk perception; preparedness perceptions such as outcome expectancy; critical awareness; optimistic and normalisation biases; self-efficacy; collective efficacy; fatalism; locus of control; previous experience; societal norms; sense of community; community participation, articulation of problems and empowerment; trust; perceived responsibility; responsibility for others; coping style; and resource issues.

These are not the only dispositional characteristics that can be invoked to account for differences in preparedness.

Self-esteem is a favourable or unfavourable attitude toward the self (Rosenberg [16]). It is an individual's sense of his/her value or worth, or the extent to which a person values, approves of, appreciates, prizes, or likes himself/herself (Blascovich and Tomaka [17]). According to (Hobfoll and Lilly [18]), self-esteem, being a robust resource, is resilient to threat of loss. Those who have built a stronger armamentarium of personal, social, economic and other sustaining resources will be better suited to adapt to possible dangers by building on their already durable resource reserves in a proactive fashion (Updegraff and Taylor [19]). Thus, people armed with a robust resource like selfesteem would show greater preparedness before the disaster strikes. Hence, selfesteem, a robust psychological resource (Hobfoll [20]), becomes the motivating factor for preparedness. People prefer to invest resource in impending disaster situations. People having high self-esteem have more sense of worth. They will protect themselves from a self-esteem threatening situation (Loewenstein and Lerner [21]).

Self-efficacy is defined as the perceived ability to organize and execute courses of action to achieve a desired outcome. This concept is shown to influence precautionary behaviour and how well people respond emotionally and behaviourally to stress. Those with positive views of their own efficacy are more likely to try harder to succeed and persist in the face of challenges (Norris [22]).

Self-efficacy reflects the perceptions of personal capacity to do something and outcome efficacy is the measuring of the perceptions of necessary actions in reducing a problem. In the present study, The "Person relative to event" model, using for earthquake preparedness, predicts that increasing levels of threat when resources are appraised as sufficient relative to the magnitude of the threat will 
increase problem-focused coping (Mulilis and Duval [23]). In the studies (Mulilis and Duval [9]), according to their resources, participants were assigned to groups as clearly sufficient, probably sufficient, and clearly insufficient relative to the magnitude of the threatening event.

Findings showed that, participants in the clearly sufficient resource condition evidenced greater change in preparedness levels than did those in the probably sufficient and clearly insufficient resources condition, and participants in the probably sufficient resource condition evidenced greater change than clearly insufficient condition (Duval and Mulilis [2]). The study of (Paton et al. [4]) in disaster preparedness showed that both self-efficacy and outcome efficacy predicted problem-focused behaviour or action coping being linked to earthquake preparedness behaviour.

Dispositional optimism refers to the anticipation that good outcome will occur when confronting major problems (Scheier and Carver [24]). This quality is considered to be a determinant of sustained efforts to deal with problems, as contrasted with turning away and giving up. Individuals that possess this quality are more likely to sustain disaster induced depression than those who do not have it. Optimism has a proven negative relationship to depression and is a strong predictor of the use of problem-focused coping strategies and better cognitive and emotional functioning (Karademas [26]).

Norris identifies optimism, hope, and self-esteem as three concepts necessary to understand resilience; defined as "the process of, capacity for or outcome of successful adaptation after trauma, adversity, or severe stress" (Norris [22]). According to Norris, optimism has been shown to be a key protective factor for disaster.

Optimists and pessimists respond and cope differently with stress. Two forms of coping with stress include problem-focused coping and emotion-focused coping. Problem-focused coping is closely related to optimism and typically shown in situations where people believe something positive can be done about the stressor. This statement agrees with the literature that says optimists are more likely to have stronger problem solving skills (Karademas [26]). Emotionfocused coping is not directly associated but rather is related to pessimism. This form of coping attempts to limit emotional distress and is employed when people feel forced to endure the situation. However, if someone feels that they cannot escape or moderate the stress, they may disengage as a response to the stressor. Problem-focused coping strategies are more concentrated on the actual stressor; while emotion focused coping strategies attempt to deal with the emotions that arise from the stressor (Nes and Segerstrom [27]).

There are multiple theoretical reasons for expecting that the stress inoculation and management components of the psychological preparedness material might be less effective for individuals characterised by moderate to high chronic anxiety (e.g., Gist and Lubin [28]; Lazarus [29]; Watson and Clark [30]).

Potential future disaster can represent a source of anxiety because of their destructive consequences. If this anxiety is present at appropriate level, there is a positive relationship between anxiety and disaster preparedness behaviour. Lazarus [29] stated that, when anxiety is dispositional in character, people tend 
to appraise any situation as threatening; and those who are high in trait-anxiety scores are more likely to take adaptive adjustments to disaster.

On the other hand, if anxiety reaches an extreme level, it can reduce the likelihood that people will prepare for disasters (Paton et al. [4]). According to the study (De Man and Simpson-Housley [31]), high trait anxiety was positively related to the perceived threat. Person "Relative to Event Model" suggested that under conditions in which resources are appraised as insufficient relative to threat, increasing absolute levels of perceived threat and anxiety will decrease problem-focused coping, and so decrease disaster preparedness behaviour (Mulilis and Duval [23]).

It was also the case that the overall level of preparedness for more highly anxious individuals might be expected to be relatively low, possibly reflecting selective avoidance strategies and an escalating experience of anticipatory stress and panic. Previous research has shown that trait anxiety is positively associated with experienced stress in an emergency situation and inversely related to physical preparedness (e.g., De Man and Simpson-Housley [31]; Dooley et al. [32]).

Despite the amount of research that has taken place, there are still gaps in our knowledge about the socio-psychological processes related to preparing (Tierney et al. [33]).

\section{The method of response functions}

All the studies of preparedness mentioned above used statistical analysis procedures such as correlation analysis, stepwise linear regression, analysis of variance, discriminant analysis, or similar statistical techniques based on the general linear model or one of its multivariate generalisations. The problem is that such approaches do not yield information about linkages between causes and effects, especially in case of nonlinearity of interactions within system under study. The limitations of such models as exploratory and predictive tools are well known and describe elsewhere (e.g. Maxwell [34]).

Modelling for studying the behaviour of large, complex systems such as psychological phenomena presents considerable difficulties. These difficulties result from the sheer complexity of internal system behaviour arising from dynamic and multidimensional nonlinear interactions. Compounding this complexity is our incapacity to measure internal system states as comprehensively and accurately as we would like, and to perturb system inputs and parameters so that we can observe and understand individual aspects of system's behaviour.

In our study we propose the 'method of response functions' (MRF) as a method of the construction of purposeful, credible integrated models from data and prior knowledge or information. Integration means capturing as much as possible of cause-effect relationships and describing them with an operator of transition, or "input-output" function. The data are usually time or spatial series observations of system inputs and outputs, and sometimes of internal states. Data series observations contain "hidden" information on the processes under 
consideration and one of the main purpose of the proposed method is to " "extract" and describe these hidden relationships. The method of response functions implies credible models in the sense that they are identifiable, and, hopefully, explains system output behaviour satisfactorily. The theory of the method of response function and its applications has been described in several articles and monograph (Malkina-Pykh and Pykh [35, 36]).

The MRF is an exploratory data analysis technique that attains this aim by condensing large amounts of data into nonlinear regression model that relays important relationships in the most economical manner. The MRF can model nonlinear relationships among variables, can handle nominal or ordinal data, and does not require multivariate normality. This approach allows us to take into account all essential features of psychological systems: complexity, multidimensionality, uncertainty, irreducibility, and so on.

Let us assume the basic definitions of the MRF. By factors we mean the system's properties that directly affect processes or characteristics under study. We designate the factors as a vector $x=\left(x_{1}, x_{2}, \ldots, x_{n}\right)$. Then, by partial response function of the characteristic or the process we mean a function which depends on a single active factor, i.e. the function of a single variable $f_{i}\left(x_{i}\right)$. In many typical cases, the graph of the partial response function $f_{i}$ to the variability of the factor $x_{i}$ is a unimodal or $S$-shape curve. By generalised response function we mean a function $F\left(x_{1}, \ldots, x_{n}\right)$ which accounts for all the factors considered and presented as a combination of partial response functions $f_{i}\left(x_{i}\right)$. A generalised response function can also be determined as an $N$-dimensional geometric figure, or its data matrix equivalent, which gives the levels of an important system response as a function of combinations of levels of the factors to which that system is exposed.

Thus it is necessary to note, that designation of the system's characteristics as factors and responses is entirely determined by statement of a problem.

Now we propose to present the generalised response function in the form

$$
F\left(x_{1}, \ldots, x_{n}\right)=\prod_{i=1}^{n} f_{i}\left(\alpha^{i}, x_{i}\right),
$$

where $n$ is the number of the factors under study, $\alpha^{i}$ is a vector of parameters, the values of which we have to determine in the process of identification. Basically, it has been criticised that the multiplicative form represents the independence of the influencing factors. We'll demonstrate later that this problem can be resolved successfully using some specific technique for the evaluation of parameters of the generalised response function $F\left(x_{1}, \ldots, x_{n}\right)$. We introduce also the additional restriction in the identification procedure:

$$
\max _{x_{i}} f_{i}\left(\alpha^{i}, x_{i}\right)=1
$$


It is evident that standardisation condition (2) gives us a possibility to compare the impact of different factors on the process under study.

The aim of the present study was to apply the method of response functions (MRF) for the development of nonlinear integrated model of individual psychological preparedness from data and prior knowledge or information on several personality variables: trait anxiety, self-efficacy, dispositional optimism and self-esteem. These independent variables were used for the construction of the PREP model. The proposed model can be applied as effective assessment tool not only for the basic level of psychological preparedness but also for indication of the most important variables for pre-impact intervention.

\section{Integrated model of psychological preparedness}

Then the model of psychological preparedness (PREP) is looking as follows:

$$
\begin{gathered}
\text { PREP } P_{\mathrm{mod}}=P R E P_{\text {norm }} \cdot F_{s t} \\
F_{s t}=f_{1}(O P T) \cdot f_{2}(E S T) \cdot f_{3}(S E F) \cdot f_{4}(A N X) \\
f_{j}\left(x_{j}\right)=\alpha_{j}\left(\frac{b_{j}}{c_{j}+\exp \left(d_{j}-\gamma_{j} \cdot x_{j}\right)}\right) \quad j=1,2,3 \\
f_{4}(A N X)=\alpha_{4}\left(b_{4}-c_{4}\left(1-\exp \left(-d_{4} \cdot A N X^{\gamma_{4}}\right)\right)\right)
\end{gathered}
$$

where $P R E P_{\text {mod }}, P R E P_{\text {norm }}$ are the actual values of psychological preparedness measure resulted from the modified Psychological Preparedness to Disaster Threat Scale (PPDTS) and mean score in the given sample, OPT are the scores of dispositional optimism, EST are the scores of self-esteem, $S E F$ are the scores of self-efficacy $A N X$ are the scores of anxiety, $F_{s t}, f_{j}$ are the generalised and partial response functions respectively, $\alpha_{j}, b_{j}, c_{j}, d_{j}, \gamma_{j}$ are parameters for evaluation, $j=1, . ., 4$.

As function (3) is nonlinear in parameters, the problem of parameter estimation can be solved only by numerical methods. The parameters are determined by minimising the sum of squared differences between estimated data and survey measurements. The corresponding parameters estimation is provided with the module "Isqnonlin" from the program package MATLAB Optimization Toolbox. We enter the coded values because the "natural" measurements of personality variables under study had different ranges that might cause difficulties for the parameter's estimation procedure. All raw scales are linearly converted to a scale from 0 to 10 , with a higher score indicating higher levels of personality variables. We identify the parameters by using several initial approximations, until the process converged to a single point and checked the obtained results using the convergence criteria for nonlinear optimisation procedure. Nevertheless, the final solution is selected according to the following guidelines of psychological relevance: (1) the selected parameter 
values should keep the residual errors between model and data as small as possible but not greater than the value of standard error of measurement; (2) parameter estimates should make psychological sense. For example, a reasonable view of the partial response function graphs should be obtained for the variables under study.

Another guideline is the absence of other solutions in the vicinity of the found solution.

\section{Future research directions}

To be able to provide the identification of parameters of PREP model and its validation we are collecting data on psychological preparedness and its psychological predictors in the sample in Novorossisk, city located on the Black Sea shore in Southern Russia where climate change disasters such as storm wind, flooding and earthquake occur now very often.

Demographic variables include age and gender. Subjects are assessed with the following measures: Self-esteem Scale (Rosenberg [16]), General Self-Efficacy Scale (Schwarzer and Jerusalem [25]), Life Orientation Test (LOT) (Scheier et al. [37]), Trait Anxiety Scale of the State-Trait Inventory (STAI) (Spielberger et al. [38]).

Disaster preparedness is evaluated with the 14-item preparedness scale based on 18-item Psychological Preparedness to Disaster Threat Scale (PPDTS) (Zulch [39]). Sample instructions and items include, "I am familiar with the severe storm or cyclone preparedness materials available to me", "I know which household preparedness measures are needed to stay safe in a very severe storm or cyclone situation", "In a severe storm or cyclone situation I would be able to cope with my anxiety and fear". Respondents are asked to indicate the extent of preparedness with regard to each item in the scale by checking either 'yes' (score $=3$ ), 'unsure' ( score $=2$ ), or 'no' ( score $=1$ ).

Russian-validated translations of all measures are used.

\section{Conclusions}

In the present study we proposed the method of response functions (MRF) for the development of nonlinear integrated model of individual psychological preparedness from data and prior knowledge or information on several personality variables: trait anxiety, self-efficacy, dispositional optimism and selfesteem. These independent variables were used for the construction of the PREP model. The proposed model can be applied as effective assessment tool not only for the basic level of psychological preparedness but also for indication of the most important variables for pre-impact intervention.

To be able to provide the identification of PREP model's parameters and its validation, at the moment we are collecting data on psychological preparedness and its psychological predictors in the sample in Novorossisk, city located on the Black Sea shore in Southern Russia where climate change disasters such as storm wind, flooding and earthquake occur now very often. 


\section{References}

[1] Morrissey, S.A. and Reser, J.P. Evaluating the effectiveness of psychological preparedness advice in community cyclone preparedness materials. Australian Journal of Emergency Management, 18, pp. 44-59, 2003.

[2] Duval, T.S. and Mulilis, J.-P. A person-relative-to-event (PrE) approach to negative threat appeals and earthquake preparedness: A field study. Journal of Applied Social Psychology, 29 (3), pp. 495-516, 1999.

[3] Hobfoll, S.E. The Ecology of Stress. Hemisphere: New York, 1988.

[4] Paton, D., Smith, L.M. and Johnston, D. When good intentions turn bad: Promoting natural hazard preparedness. Australian Journal of Emergency Management, 20, pp. 25-30, 2005.

[5] Reser, J.P. and Morrissey, S.A. The crucial role of psychological preparedness for disasters. InPsych: The Bulletin of the Australian Psychological Society, 31(2), pp. 14-15, 2009.

[6] Zeidner, M. and Endler, N.S. (Eds). Handbook of Coping: Theory, Research, Applications. Wiley: New York, 1996.

[7] Lindell, M.K. and Perry, R.W. Behavioral Foundations of Community Emergency Planning. Hemisphere Publishing: Washington, 1992.

[8] Aspinwall, L.G. and Taylor, S.E. A stitch in time: Self-regulation and proactive coping. Psychological Bulletin, 121, pp. 417-436, 1997.

[9] Mulilis, J.-P. and Duval, T.S. Negative threat appeals and earthquake preparedness: A person-relative-to-Event (PrE) model of coping with threat, Journal of Applied Social Psychology, 25, pp. 1319-1339, 1995.

[10] Bishop, B., Paton, D., Syme, G. and Nancarrow, B. Coping with environmental degradation: Salination as a community stressor. Network, 12(1), pp. 1-15, 2000.

[11] Mulilis, J-P., Duval, T. S. and Rombach, D. Personal responsibility for tornado preparedness: Commitment or choice? Journal of Applied Social Psychology, 31(8), pp. 1659-1688, 2001.

[12] Sims, J.H. and Bauman, D.D. Educational programs and human response to natural hazards. Environment and Behaviour, 15(2), pp. 165-189, 1983.

[13] Bauman, D.D. and Sims, J.H. The tornado threat: Coping styles of the north and south. Science, 176 (4040), pp. 1386-1392, 1972.

[14] Yates, S., Axsom, D. and Tideman, K. The help seeking process for distress after disasters. In R. Gist and B. Lubin (Eds.). Response to Disasters. Taylor and Francis: Philadelphia, pp. 133-158, 1999.

[15] Becker, J.S., Johnston, D.M., Paton, D. and Ronan, K. How people use earthquake information and its influence on household preparedness in New Zealand. Journal of Civil Engineering and Architecture, 6(6), pp. 673-681, 2012.

[16] Rosenberg, M. Society and the Adolescent Self-image. Princeton University Press: Princeton, NJ, 1965.

[17] Blascovich, J. and Tomaka, J. Measures of self-esteem. In J. P. Robinson, P. R. Shaver, and L. S. Wrightsman (Eds.) Measures of Personality and 
Social Psychological Attitudes, Volume I. Academic Press: San Diego, CA, pp. 115-160, 1991.

[18] Hobfoll, S.E. and Lilly, S.R. Resource conservation as a strategy for community psychology. Journal of Community Psychology, 21(1), pp. 128148, 1993.

[19] Updegraff, J.A. and Taylor, S.E. From vulnerability to growth: Positive and negative effects of stressful life events. In J. H. Harvey and E. D. Miller (Eds.), Handbook of Loss and Trauma, Bruner/Mazel: NY, pp. 3-28, 2000.

[20] Hobfoll, S.E. Conservation of resource: A new attempt at conceptualising stress. American Psychologist, 44(3), pp. 513-524, 1989.

[21] Loewenstein, G., and Lerner J. The role of emotion in decision making. In R.J. Davidson, H.H. Goldsmith, and K.R. Scherer (Eds.), Handbook of Affective Science. Oxford University Press: Oxford, England, pp. 619-642, 2003.

[22] Norris, F.H. Behavioral science perspectives on resilience. CARRI Research Report 10, pp. 1-50, http://www.resilientus.org/library/ Behav_Science_Perspectives_fn_1309545968.pdf, 2010.

[23] Mulilis, J.-P. and Duval, T.S. The PrE model of coping with threat and Tornado preparedness behavior: the moderating effects of felt responsibility. Journal of Applied Social Psychology, 27, pp. 1750-1766, 1997.

[24] Scheier, M.F. and Carver, C.S. Optimism, coping, and health: Assessment and implications of generalized outcome expectancies. Health Psychology, 4, pp. 219-247, 1985.

[25] Schwarzer, R. and Jerusalem, M. Generalized Self-Efficacy scale. In J. Weinman, S. Wright, and M. Johnston, Measures in Health Psychology: A User's Portfolio. Causal and Control Beliefs. NFER-NELSON: Windsor, UK, pp. 35-37, 1995.

[26] Karademas, E.C. Self-efficacy, social support and well-being: The mediating role of optimism. Personality and Individual Differences, 40, pp. 1281-1290, 2006.

[27] Nes, L.S. and Segerstrom, S.C. Conceptualizing coping: optimism as a case study. Social and Personality Psychology Compass, 2, pp. 2125-2140, 2008.

[28] Gist, R. and Lubin, B. Psychosocial Aspects of Disaster. New York: John Wiley: New York, 1989.

[29] Lazarus, R.S. Emotion and adaptation. Oxford University Press: Oxford, 1991.

[30] Watson, D. and Clark, L.A. Negative affectivity: The disposition for experiencing aversive emotional states. Psychological Bulletin, 96, pp. 465-490, 1984.

[31] De Man, A.F. and Simpson-Housely, P. Factors in perception of earthquake hazard. Perceptual and Motor Skills, 64, pp. 815-820, 1987.

[32] Dooley, D., Catalano, R., Mishra, S. and Serxner, S. Earthquake preparedness predictors in a community survey. Journal of Applied Social Psychology, 22, pp. 451-470, 1992. 
[33] Tierney, K.J., Lindell, M.K. and Perry, R.W. Facing the Unexpected: Disaster Preparedness and Response in the United States. Joseph Henry Press: Washington DC, 2001.

[34] Maxwell, A.E. Limitations of the use of the multiple linear regression model. British Journal of Mathematical and Statistical Psychology, 28, pp. 51-62, 1975.

[35] Malkina-Pykh, I.G., and Pykh, Yu.A. Integrated modeling of subjective well-being: Psychological predictors and method of response functions. Ecological Indicators, 28, pp. 150-158, 2013a.

[36] Malkina-Pykh, I.G. and Pykh, Yu.A. The Method of Response Function in Psychology and Sociology. WIT Press: Southampton, Boston, 2013b.

[37] Scheier, M.F., Carver, C.S. and Bridges M. Distinguishing optimism from neuroticism (and trait anxiety, self-mastery, and self-esteem): A reevaluation of the Life Orientation Test. Journal of Personality and Social Psychology, 67, pp. 1063-1078, 1994.

[38] Spielberger, C.D., Gorsuch, R.L., Lushene, R., Vagg, P.R. and Jacobs, G.A. Manual for the State-Trait Anxiety Inventory. Consulting Psychologists Press: Palo Alto, CA, 1983.

[39] Zulch, H.R. Psychological preparedness for natural disasters in the context of climate change // http://www.griffith.edu.au/research/researchexcellence/griffith-climate-change-response-program, 2011. 